\title{
RANCANG BANGUN ALAT UKUR KADAR KLOROFIL DAUN KARET (Hevea brasiliensis) MENGGUNAKAN METODE TRANSMISI CAHAYA
}

\author{
Nehru*, Muhammad Rido, Muhammad Ficky Afrianto, Radi Purbakawaca \\ Fisika, Fakultas Sains dan Teknologi, Universitas Jambi, Jl. Jambi-Ma. Bulian, Km. 15, Jambi, 36361, Indonesia \\ ${ }^{8}$ e-mail:nehruunja@gmail.com
}

\begin{abstract}
ABSTRAK
Telah dibuat rancang bangun alat ukur kadar klorofil daun karet (Hevea brasiliensis) menggunakan metode transmisi cahaya. Alat ukur dirancang menggunakan sistem kontrol Arduino Mega 2560. Arduino akan mengontrol semua kinerja alat ukur kadar klorofil yang terdiri dari sensor warna TCS3200, layar, button control, SD Card, dan RTC. Metode pengukuran kadar klorofil menggunakan metode transmisi cahaya dari sumber LED RGB yang ditembakkan pada daun karet dan kemudian hasil cahaya transmisi dari daun karet ditangkap oleh sensor warna TCS3200. Ouput dari sensor warna yaitu berupa frekuensi gelombang kotak yang dikonversi menjadi nilai RGB dan kemudian dikonversi lagi menjadi kadar klorofil. Alat ukur hasil rancang bangun memiliki akurasi sebesar 85,50\% dan memiliki keofesien relasi antara klorofil aktual dengan klorofil model sebesar 81,06\%.
\end{abstract}

Kata Kunci: Daun Karet, Klorofil, Arduino Mega 2560, Sensor Warna TCS3200, Transmisi Cahaya

\section{ABSTRACT}

[ Title: Design Of Measuring Instrument For Rubber Leaf (Havea Brasiliesis) Chlorophyll Content Using Light Transmission Methods] Design of measuring instruments for rubber leaf chlorophyll (Hevea brasiliensis) has been made using light transmission method. The measuring instrument is designed using the Arduino Mega 2560 control system. Arduino will control all performance measuring instruments for chlorophyll levels consisting of TCS3200 color sensors, screen, button control, SD Card, and RTC. Chlorophyll levels measurement method using light transmission of RGB LED sources are emitted into the rubber leaf and then the result of the transmission of light captured by the sensor rubber leaf TCS3200 color. Output from the color sensor in the form of square wave frequency is converted into $R G B$ values and then converted again into the chlorophyll levels. The design measurement tool has an accuracy of $85.50 \%$ and has a keofesien relation between the actual chlorophyll and the chlorophyll model of $81.06 \%$.

Keywords: Rubber Leaves, Chlorophyll, Arduino Mega 2560, TCS3200 Color Sensor, Light Transmission

\section{PENDAHULUAN}

Karet merupakan komoditas yang banyak dibudidayakan di Indonesia. Posisi geografis berada di sekitar iklim tropis menyebabkan peluang budidaya karet sangat besar. Salah satu yang banyak membudidayakan karet adalah Provinsi Jambi. Dalam artikel Irawan (2017), pertumbuhan perekonomian di Jambi pada tahun 2017 meningkat yang diakibatkan karena membaiknya produksi dan kenaikan harga karet.

Hasil perkebunan karet adalah dalam bentuk lateks. Berdasarkan bps.go.id, produktivitas lateks di jambi cukup tinggi mencapai 328.581 ton dan 334.463 ton pada tahun 2015 dan 2016. Namun terkadang ada masa di mana produktivitasnya menurun. Salah satu penyebab menurunnya produktivitas tersebut adalah karena kadar klorofil yang rendah pada daun karet yang mengakibatkanproses fotosintesisnya terhambat. Oleh karena itu diperlukan pendeteksian kadar klorofil sejak dini.

Pengukuran kadar klorofil dapat dilakukan dengan berbagai cara, seperti dengan melakukan ekstraksi daun karet yang kemudian dilakukan analisis menggunakan spektrofotometer (Rustami, 2017). Pengukuran ini tidaklah praktis karena diperlukan laboran untuk melakukan analisis kadar klorofil. Namun seiring berkembangnya alat ukur kadar klorofil, dewasa ini telah tersedia di pasar, yaitu SPAD-502 buatan Konica Minolta Optics Inc dari Osaka, Jepang. Alat ukur ini digunakan secara umum untuk pengukuran secara cepat dan tidak merusak klorofil relatif pada daun. Alat ukur ini bekerja dengan menjepit daun, kemudian mentransmisikan 
cahaya melalui daun pada panjang gelombang 650nm dan 940nm (Zhu et al., 2012). Namun alat ukur ini tidak ekonomis, sehingga akan memberatkan ekonomi petani untuk melakukan pengukuran kadar klorofil.

Sejauh ini, perkembangan teknologi dibidang elektronika telah memberikan peluang bagi para peneliti untuk membuat suatu instrumen yang lebih presisi, mudah digunakan, dan ekonomis (Rustami, 2017). Dalam bidang elektronika terdapat teknologi mikrokontroller, di mana proses kerja dari rangkaian elektronika dikendalikan oleh chip. Dewasa ini pengaplikasian mikrokontroller sangat luas, terutama dalam sistem elektronika modern (Andrianto, 2016). Oleh karena itu, alat ukur kadar klorofil dimungkinkan dapat dibuat dengan perekayasaan logika dan algoritma pada mikrokontroller yang diintegrasikan dengan sensor dan aktuator.

Berdasarkan permasalahan tersebut, maka dianggap perlu melakukan penelitian untuk pembuatan alat ukur kadar klorofil. Pada penelitian ini akan dibuat alat ukur kadar klorofil menggunakan mikrokontroller Arduino Mega 2560. Sensor yang digunakan adalah sensor warna sebagai pendeteksian warna dari daun karet dengan memanfaatkan nilai RGB yang terdeteksi. Metode yang akan digunakan adalah metode transmisi cahaya, karena pada alat SPAD-502 pengukuran berbasis absorbansi cahaya dengan panjang gelombang tertentu cahaya yang diklaim memiliki nilai akurasi sebesar $\pm 100 \%$, sehingga diharapkan alat ukur yang dibuat dapat digunakan sebagai alat ukur klorofil dan mampu mendapat nilai akurasi yang cukup baik.

\section{METODOLOGI PENELITIAN}

\section{Tempat dan Waktu}

Penelitian dilakukan di Labroratoriumm Energi Rekayasa dan Material, Laboratorium Bieteknologi dan Rekayasa, Fakultas Sains dan Teknologi, Universitas Jambi, dan Laboratorium Dasar dan Terpadu Universitas Jambi. Penelitian dilakukan selama 3 bulan yang mencakup keseluruhan tahap penelitian.

\section{Bahan dan Peralatan}

Bahan yang digunakan terdiri dari Arduino Mega2560, kapasitor smd $(22 \mathrm{nF}, 0.1 \mathrm{uF})$, resistor smd $(10 \mathrm{~K} \Omega, 4.7 \mathrm{~K} \Omega, 100 \Omega)$, push button, colour sensor TCS3200, white smd LED (Light Emitting Diode), smd RTC (Real Time Clock) DS1307, battery holder CR1220, lithium battery 3V CR1220, OLED (Organic Light Emitting Diode) display 0.93 inch, kabel, male header, female header, buzzer, micro SD socket, micro SD card, AMS117 3.3V, male header pin, saklar, kertas transfer paper, PCB polos, timah solder, lotfet, daun daun karet dengan umur daun yang berbeda. Peralatan yang digunakan terdiri dari, solder biasa, solder uap, penyangga solder, pinset, penyedot timah, obeng, cutter, nampan pelastik kecil, $\mathrm{FeCl}_{3}$, air, tisu, printer laser, Spektrofotometer UV Vis, mortar, pipet, tabung reaksi, rak tabung reaksi, gelas ukur, corong, gelas piala, kertas saring, alumunium foil, dan aseton $80 \%$. Untuk mendesain dan memrogram alat digunakan laptop, software Arduino IDE (Integrated Development Environment) 1.8.0, software EAGLE 7.7.0., dan software CorelDRAW X7.

\section{Perancangan dan Pembuatan Alat}

Perancangan alat dilakukan dengan membuat desain tampilan pada display alat, diagram blok alat, skema umum alat, skematik rangkaian, dan $\mathrm{PCB}$ (Printed Circuit Board). Tampilan pada display didesain menggunakan software Corel Draw X7 dengan resolusi 128 x 64 pixel dari layar OLED 0,96". Diagram blok dan skema umum alat juga didesain menggunakan software Corel Draw X7. Skematik rangkaian dan PCB dibuat menggunakan software Eagle 7.7.0 yang dibuat sesuai dengan diagram blok skema alat.

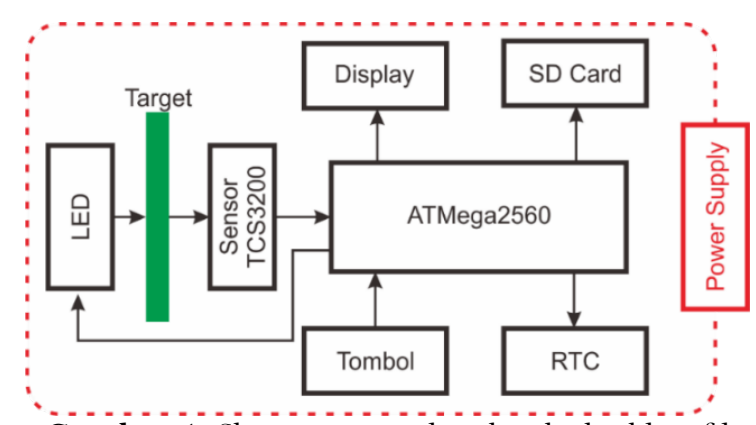

Gambar 1. Skema umum alat ukur kadar klorofil

Alat ukur dibuat menggunakan mikrokontroller Arduino Mega 2560 yang diprogram menggunakan software Arduino IDE. Sensor yang digunakan untuk menangkap warna dari transmisi cahaya tampak polikromatik dari sumber cahaya LED. Cahaya tersebut diteruskan melalui target, berupa daun yang akan ditangkap oleh sensor. Alat ukur diintegrasikan dengan display, RTC, SD card, dan tombol. Fungsi dari beberapa komponen adalah sebagai berikut, display digunakan untuk user interface, RTC digunakan untuk memberikan informasi waktu ketika user mengukur kadar klorofil, SD Card digunakan untuk menyimpan data kadar klorofil, dan tombol digunakan untuk mengontrol menu yang akan dipilih pada display. 


\section{Karakterisasi Sensor TCS3200}

Karakterisasi sensor dilakukan dengan pendeteksian warna. Target yang akan dideteksi adalah plastik warna transparan. Plastik yang digunakan ada 6 macam, yaitu merah, kuning, hijau, biru, tak berwarna, dan tak tembus cahaya. Output sensor diskalakan berdasarkan setting pin S0 dan S1 pada sensor. Frekuensi output sensor akan disetting dengan 3 skala berdasarkan tabel 1, kemudian diukur menggunakan osiloskop dan Arduino Mega 2560. Pengukuran di Arduino Mega 2560 akan menggunakan fungsi pulseIn() di Arduino. Hasil pengukuran osiloskop dan Arduino Mega 2560 akan dibandingkan, sehingga dapat diketahui linearitas dari kedua pengukuran tersebut.

Tabel 1. Pemilihan logika pin S0 dan S1 sebagai output skala frekuensi

\begin{tabular}{ccl}
\hline S0 & S1 & \multicolumn{1}{c}{ Output Skala Frekuensi } \\
\hline L & L & Power Down \\
L & H & $2 \%$ \\
H & L & $20 \%$ \\
H & H & $100 \%$ \\
\hline
\end{tabular}

L dan $\mathrm{H}$ adalah sinyal $L O W(0)$ dan $H I G H$ (1) yang diberikan pada pin S0 dan S1 untuk pemilihan output skala frekuensi.

\section{Konversi Nilai Frekuensi ke RGB}

Output sensor akan menghasilkan frekuensi yang berbeda-beda pada masing-masing filter warna. Frekuensi tersebut masih belum dalam nilai RGB, dimana nilai RGB akan memiliki nilai minimum dan maksimum 0 - 255. Untuk mengkonversi nilai frekuensi ke RGB, dihitung menggunakan persamaan 1 dengan hanya menggunakan filter $\mathrm{R}, \mathrm{G}$, dan $\mathrm{B}$, sehingga

$$
r=255 \frac{F_{r}}{F_{r p}} ; g=255 \frac{F_{g}}{F_{g p}} ; b=255 \frac{F_{b}}{F_{b p}}
$$

Dimana $r, g, b$ merupakan nilai RGB, $F_{r}, F_{g}, F_{b}$ merupakan frekuensi yang di ukur, dan $F_{r p}, F_{g p}, F_{b p}$ merupakan frekuensi nilai maksimum bacaan sensor

\section{Pengumpula n Data Klorofil}

Pengumpulan data klorofil dilakukan dengan pengukuran nilai RGB terlebih dahulu pada daun karet yang kemudian pada daun yang sama dilakukan ekstraksi sebagai pengukuran kadar klorofil aktual. Hasil ekstraksi daun karet kemudian diukur nilai absorbansinya pada panjang belombang $646 \mathrm{~nm}$ dan $663 \mathrm{~nm}$ dengan blanko aseton 80\%. Kadar klorofil dihitung menggunakan persamaan 2
Klorofil total $(\mathrm{mg} / \mathrm{L})=(17.3 \times \mathrm{A} 646)+(7.18 \times$ A663)

dengan A646 adalah absorbansi pada panjang gelombang $646 \mathrm{~nm}$, dan A663 adalah absorbansi pada panjang gelombang $663 \mathrm{~nm}$ (Harborne, 1987).

\section{Konversi Nilai RGB ke Kadar Klorofil}

Konversi ini dilakukan setelah nilai RGB dan kadar klorofil aktual telah didapatkan. Kedua nilai tersebut dihitung menggunakan polinomial multivariabel

$$
\begin{aligned}
P= & a_{0}+a_{1} R+a_{2} R^{2}+a_{3} R^{3}+b_{0}+b_{1} G+ \\
& b_{2} G^{2}+b_{3} G^{3}+c_{0}+c_{1} B+c_{2} B^{2}+c_{3} B^{3}
\end{aligned}
$$

Hasil konversi kemudian diplotting untuk melihat koefesien korelasi antara nilai RGB dengan kadar klorofil.

\section{Validasi Alat Ukur Kadar Klorofil}

Validasi dilakukan dengan membandingkan hasil ukur alat prototype dengan hasil ukur menggunakan spektrofotometer. Data hasil pengukuran kemudian akan dianalisis dengan menghitung nilai error (persamaan 4) dan akurasi (persamaan 5). Hasil analisis kemudian ditampilkan dalam bentuk grafik.

$$
\begin{gathered}
\text { error }=\left|\frac{\text { nilai ukur-nilai sebenarnya }}{\text { nilai sebenarnya }}\right| \times 100 \% \\
\text { akurasi }=100 \%-\text { error }
\end{gathered}
$$

\section{HASIL DAN PEMBAHASAN}

\section{Fabrikasi Alat dan Uji Blok Fungsional}

Fabrikasi dilakukan dengan menggabungkan semua rangkaian yang terdiri dari layar, sensor TCS3200, tombol, RTC, SD card, LED, dan mikrokontroller arduino. Layar, sensor TCS3200, tombol, RTC, SD card, dan LED disolder pada papan $\mathrm{PCB}$, sedangkan arduino dihubungkan dengan konektor pin header male. Papan PCB layar, sensor TCS3200, tombol, RTC, dan SD card yang telah disolder pada PCB terpisah dengan papan PCB yang tersolder oleh LED. Hal ini dilakukan agar LED dapat menembakkan cahaya langsung tepat pada sensor TCS3200, sehingga objek yang diukur dapat ditembakkan cahaya dan meneruskan cahaya tepat pada sensor TCS3200. Posisi antara papan PCB layar, sensor TCS3200, tombol, RTC, dan SD card dengan PCB LED dihubungkan dengan kabel agar dapat berfungsi. Hasil uji blok fungsional dari masingmasing sistem telah memiliki hasil yang cukup baik sehingga alat ukur dapat digunakan pada tahap selanjutnya. 


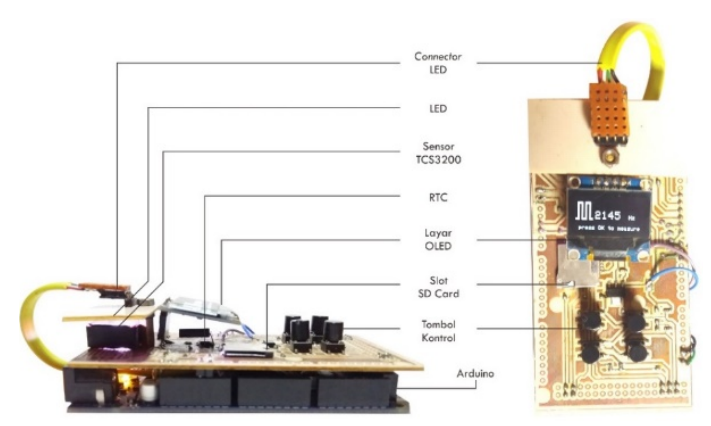

Gambar 2. Alat ukur kadar klorofil yang telah terintegrasi sekaligus bagian-bagiannya

\section{Algoritma Kerja Alat Ukur Kadar Klorofil}

Alat diawali dengan menampilkan menu utama yang di dalamnya terdapat 4 fungsi menu. Menu utama terdiri dari menu pengukuran, menu checking komponen, menu waktu, dan menu tentang alat. Pada menu utama, jika cursor berada pada posisi 1, maka tampilan akan beralih pada menu pengukuran, jika cursor berada pada posisi 2, maka tampilan akan beralih pada menu checking komponen RTC dan SD card, jika cursor berada pada posisi 3, maka tampilan akan beralih pada menu waktu, jika cursor berada pada posisi 4 , maka tampilan akan beralih pada menu info.

Pada menu pengukuran terdapat 2 pilihan, yaitu data yang akan disimpan dan data yang tidak akan disimpan. Pada tampilan ini, user akan ditanya "Apakah data ini akan disimpan?" (Gambar 3a). Jika memilih "Tidak", maka tampilan akan langsung beralih pada menu pengukuran kadar klorofil tanpa menyimpan data hasil pengukuran (Gambar 3b). Jika memilih "Ya", maka arduino akan memproses pendeteksian SD card. Jika SD card belum terpasang, maka akan ada perintah untuk memasukkan SD card. Namun pada alat yang telah dibuat, terdapat sebuah bug yang belum diketahui, sehingga ketika arduino tidak mendeteksi adanya SD card, alat ini akan crash dan tidak melakukan perintah apapun, kecuali SD card dimasukkan atau dengan menekan tombol reset arduinonya. Jika SD card telah terdeteksi, maka user akan diperintahkan untuk menginput nama file (Gambar 3c). Nama file yang dibuat minimal 1 huruf, dan maksimal 5 huruf. Input nama dilakukan dengan 4 tombol, yaitu tombol "Left" dan "Right" digunakan untuk memindahkan cursor ke kanan dan ke kiri, dan fungsi tombol "Ok" dan "Back" akan berubah fungsi sebagai " $U p$ " dan "Down". Tombol " $U_{p}$ " digunakan untuk mengubah huruf dari A hingga Z, dan "Down" dari $Z$ hingga A. Jika nama file telah diinput, maka akan beralih pada pengukuran (Gambar 3b).

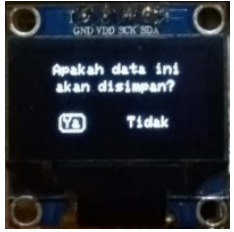

(a)

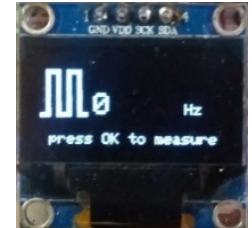

(b)

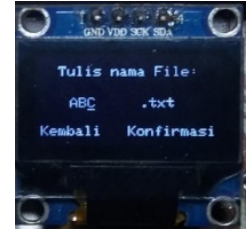

(c)
Gambar 3. (a) Pertanyaan apakah data akan disimpan atau tidak?; (b) Pengukuran kadar klorofil; (c) Input nama file yang akan disimpan pada $S D$ card

Pada menu checking komponen, RTC dan SD card akan dideteksi oleh arduino. Jika RTC dan SD card terdeteksi, maka tampilan akan menampilkan tanda centang ( $($, dan jika tidak, maka akan menampilkan tanda silang $(\times)$ (Gambar 4a). Pada menu waktu, tampilan akan menampilkan hari, tanggal:bulan:tahun, dan jam:menit:detik (Gambar 4b). Pada menu info, maka akan ada 2 menu yaitu menu "Cara Penggunaan" dan "Tentang Alat" (Gambar 4c). Pada menu "Cara Penggunaan" akan memberikan informasi cara pengguanaan alat (Gambar 4d), dan pada menu "Tentang Alat" akan memberikan informasi pembuat alat (Gambar 4e).

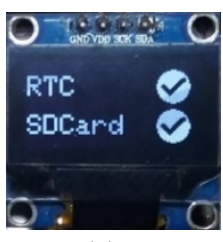

(a)

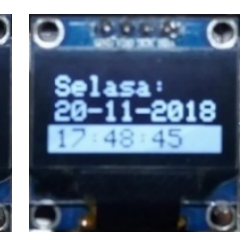

(b)

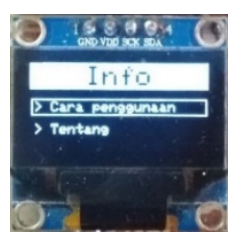

(c)

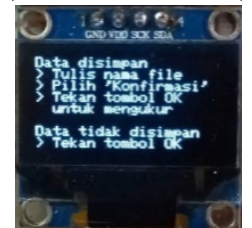

(d)

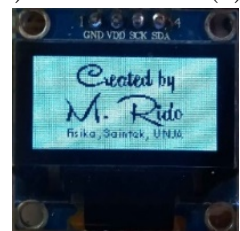

(e)
Gambar 4. (a) Tampilan checking komponen; (b) Tampilan waktu; (c) Tampilan info; (d) Tampilan cara penggunaan; (e) Tampilan pembuat alat

\section{Pendeteksian Awal}

Pendeteksian tahap awal dilakukan dengan mendeteksi plastik transparan merah, kuning, hijau, biru, tanpa objek, dan triplek (objek tak tembus cahaya). Objek tersebut ditembakkan cahaya polikromatik yang berasal dari LED RGB, kemudian cahaya yang ditransmisikan oleh objek akan diterima oleh sensor. Sinyal output dari sensor diukur menggunakan arduino dan osiloskop. Untuk pengukuran tersebut, maka alat ukur disusun bersama dengan osiloskop seperti gambar 5. Output dari sensor TC3200 masuk ke dalam pin digital dari arduino dan chanel 2 dari osiloskop. 


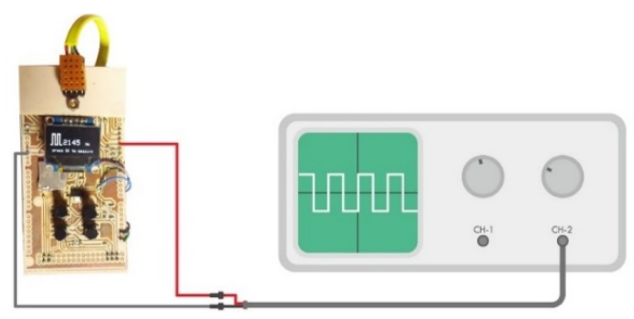

Hasil pengukuran frekuensi output sensor yang diukur dengan arduino dan osiloskop untuk masing-masing skala frekuensi 2\%, 20\%, dan $100 \%$ secara berurutan ditampilkan pada tabel 2, 3, dan 4 .

Gambar 5. Skematik rangkaian untuk melakukan pengukuran frekuensi menggunakan arduino dan osiloskop

Tabel 2. Data frekuensi gelombang output dari sensor TCS3200 pada skala frekuensi 2\%

\begin{tabular}{|c|c|c|c|c|c|c|}
\hline \multirow[b]{2}{*}{ Objek } & \multicolumn{3}{|c|}{ Osiloskop } & \multicolumn{3}{|c|}{ Alat } \\
\hline & $\begin{array}{l}\text { Avg. Red } \\
(\mathrm{Hz})\end{array}$ & $\begin{array}{c}\text { Avg. Green } \\
(\mathrm{Hz})\end{array}$ & $\begin{array}{l}\text { Avg. Blue } \\
(\mathrm{Hz})\end{array}$ & $\begin{array}{l}\text { Avg. Red } \\
(\mathrm{Hz})\end{array}$ & $\begin{array}{c}\text { Avg. Green } \\
(\mathrm{Hz})\end{array}$ & $\begin{array}{l}\text { Avg. Blue } \\
(\mathrm{Hz})\end{array}$ \\
\hline Tanpa Objek & 12500,00 & 7464,71 & 13157,89 & 9453,60 & 7340,34 & 8805,48 \\
\hline Plasik Merah & 10638,29 & 809,09 & 1544,12 & 6115,80 & 572,20 & 1252,00 \\
\hline Plastik Kuning & 13157,89 & 4751,90 & 4761,91 & 7836,80 & 3304,80 & 3678,80 \\
\hline Plastik Hijau & 769,23 & 4651,16 & 6666,67 & 478,40 & 3272,00 & 5305,60 \\
\hline Plastik Biru & 4761,90 & 5682,54 & 10416,67 & 2903,40 & 4011,60 & 9775,20 \\
\hline Triplek & 29,41 & 28,57 & 37,74 & 17,00 & 16,40 & 34,00 \\
\hline
\end{tabular}

Tabel 3. Data frekuensi gelombang output dari sensor TCS3200 pada skala frekuensi 20\%

\begin{tabular}{lcrrrrr}
\hline \multicolumn{1}{c}{ Objek } & \multicolumn{3}{c}{ Osiloskop } & \multicolumn{3}{c}{ Alat } \\
& \multicolumn{1}{c}{$\begin{array}{c}\text { Avg. Red } \\
(\mathrm{Hz})\end{array}$} & $\begin{array}{c}\text { Avg. Green } \\
(\mathrm{Hz})\end{array}$ & \multicolumn{1}{c}{$\begin{array}{c}\text { Avg. Blue } \\
(\mathrm{Hz})\end{array}$} & \multicolumn{1}{c}{$\begin{array}{c}\text { Avg. Red } \\
(\mathrm{Hz})\end{array}$} & $\begin{array}{c}\text { Avg. Green } \\
(\mathrm{Hz})\end{array}$ & $\begin{array}{c}\text { Avg. Blue } \\
(\mathrm{Hz})\end{array}$ \\
\hline Tanpa Objek & 125000,00 & 74074,07 & 131578,95 & 105000,00 & 71428,00 & 125000,00 \\
Plasik Merah & 104166,67 & 9090,91 & 15151,51 & 93333,20 & 5642,60 & 15625,00 \\
Plastik Kuning & 119047,62 & 52361,67 & 45252,52 & 100000,00 & 34761,60 & 50000,00 \\
Plastik Hijau & 7407,41 & 48780,49 & 66666,67 & 4504,40 & 32916,40 & 83333,00 \\
Plastik Biru & 47619,05 & 60606,06 & 96153,85 & 30146,60 & 40384,00 & 125000,00 \\
Triplek & 294,12 & 322,58 & 270,35 & 196,00 & 188,20 & 298,40 \\
\hline
\end{tabular}

Tabel 4. Data frekuensi gelombang output dari sensor TCS3200 pada skala frekuensi 100\%

\begin{tabular}{|c|c|c|c|c|c|c|}
\hline \multirow[b]{2}{*}{ Objek } & \multicolumn{3}{|c|}{ Osiloskop } & \multicolumn{3}{|c|}{ Alat } \\
\hline & $\begin{array}{l}\text { Avg. Red } \\
(\mathrm{Hz})\end{array}$ & $\begin{array}{c}\text { Avg. Green } \\
(\mathrm{Hz})\end{array}$ & $\begin{array}{c}\text { Avg. Blue } \\
(\mathrm{Hz})\end{array}$ & $\begin{array}{c}\text { Avg. Red } \\
(\mathrm{Hz})\end{array}$ & $\begin{array}{c}\text { Avg. Green } \\
(\mathrm{Hz})\end{array}$ & $\begin{array}{c}\text { Avg. Blue } \\
(\mathrm{Hz})\end{array}$ \\
\hline Tanpa Objek & 625000,00 & 370370,37 & 666666,67 & 400000,00 & 500000,00 & 500000,00 \\
\hline Plasik Merah & 500000,00 & 40000,00 & 71428,57 & 500000,00 & 33834,20 & 76190,00 \\
\hline Plastik Kuning & 588235,29 & 232558,14 & 227272,73 & 500000,00 & 250000,00 & 325000,00 \\
\hline Plastik Hijau & 34482,76 & 238095,24 & 333333,33 & 31250,00 & 250000,00 & 500000,00 \\
\hline Plastik Biru & 217391,30 & 285714,29 & 526315,79 & 250000,00 & 450000,00 & 500000,00 \\
\hline Triplek & 1562,50 & 1250,00 & 1388,89 & 1393,60 & 1119,80 & 1521,80 \\
\hline
\end{tabular}

Tabel 2, 3, dan 4 menunjukkan perubahan nilai frekuensi dengan perlakuan memberikan objek berwarna transparan. Semakin warna objek mendekati filter warna yang digunakan, maka besar frekuensi yang terukur juga semakin besar. Namun besar frekuensi juga dipengaruhi oleh intensitas 
cahaya yang diterima oleh sensor. Hal ini ditunjukkan oleh pemberian objek triplek dan tanpa objek. Pada pemberian perlakuan triplek, di mana cahaya tidak menembus triplek, sehingga intensitas cahaya yang diterima oleh sensor cenderung sangat kecil, dan frekuensi yang terukur sangat kecil. Sebaliknya pada pemberian perlakuan tanpa objek, intensitas cahaya yang diterima oleh sensor akan lebih maksimal, dan hasil frekuensi yang terukur jauh lebih besar.

Hasil kedua pengukuran frekuensi antara arduino dengan osiloskop kemudian dibandingkan dan dianalisis dengan metode linier seperti yang ditunjukkan pada gambar 6 .

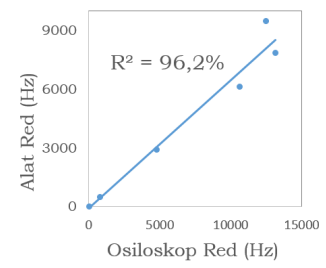

(a)

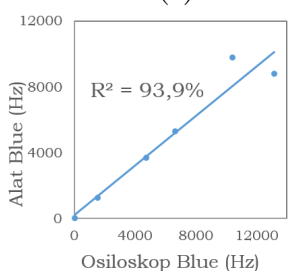

(c)

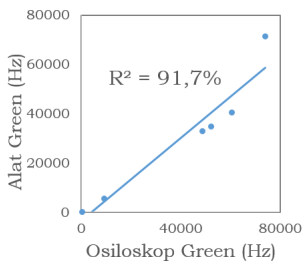

(e)

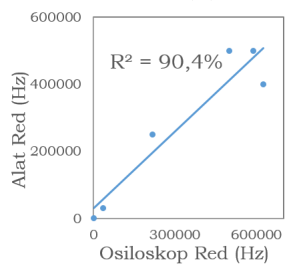

( $g$ )

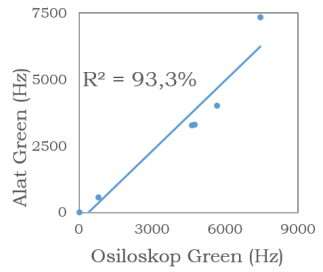

(b)

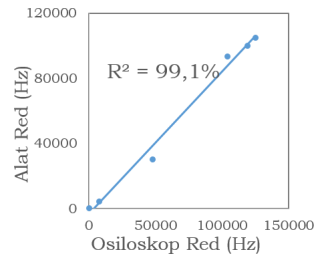

(d)

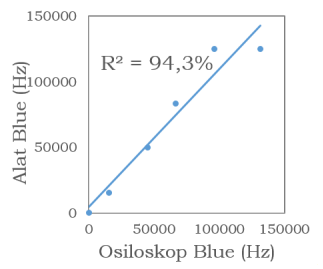

(f)

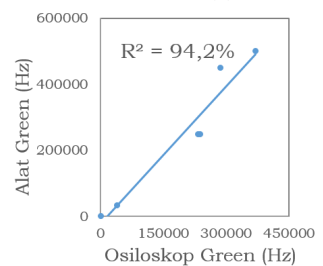

(h)

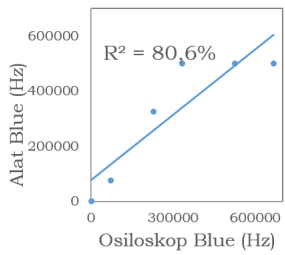

(i)

Gambar 6. Grafik perbandingan hasil ukur antara arduino dengan osiloskop pada skala frekuensi 2\%

(a)(b)(c), 20\% (d)(e)(f), 100\%(g)(h)(i).

Grafik tersebut menunjukkan bahwa nilai $\mathrm{R}^{2}$ ketiga filter cukup bagus dalam pengukuran suatu objek, sehingga mikrokontroller dan sensor yang digunakan cukup baik untuk digunakan dalam pengukuran kadar klorofil. Namun pada filter biru dengan skala frekuensi $100 \%, \mathrm{R}^{2} \geq 85 \%$, sehingga pada skala frekuensi $100 \%$ tidak disarankan untuk digunakan dalam pengukuran kadar klorofil.

\section{Konversi Nilai Frekuensi ke Nilai RGB}

Konversi frekuensi ke nilai RGB menggunakan persamaan 1, namun karena frekuensi terendah yang diukur oleh arduino adalah $\neq 0$, maka menggunakan interpolasi linier.

$$
\frac{x-x_{1}}{x_{2}-x_{1}}=\frac{y-y_{1}}{y_{2}-y_{1}}
$$

Dimana $x$ adalah nilai RGB yang disimbolkan dengan $r, g, b, x_{1}$ adalah nilai minimum RGB yaitu $0, x_{2}$ adalah nilai maksimum RGB yaitu 255, y adalah frekuensi terukur yang disimbolkan dengan $F_{r, g, b}, y_{l}$ adalah frekuensi minimum dari hasil pengukuran arduino masing-masing filter yang disimbolkan dengan $F_{r m, g m, b m}, y_{2}$ adalah frekuensi maksimum dari hasil pengukuran arduino masing-masing filter yang disimbolkan dengan $F_{r p, g p, b p}$, sehingga

$$
\begin{gathered}
r=\frac{F_{r}-F_{r m}}{F_{r p}-F_{r m}} \times 255, \quad g=\frac{F_{g}-F_{g m}}{F_{g p}-F_{g m}} \times 255, \\
b=\frac{F_{b}-F_{b m}}{F_{b p}-F_{b m}} \times 255
\end{gathered}
$$

\section{Konversi dan Kalibrasi Nilai RGB ke Kadar Klorofil}

Dilakukan pendeteksian nilai RGB terlebih dahulu pada daun karet. Nilai RGB daun karet yang dideteksi oleh sensor ditampilkan pada tabel 5 .

Tabel 5. Nilai RGB hasil pengukuran daun karet

\begin{tabular}{cccc}
\hline Sampel & R & G & B \\
\hline S1 & 17 & 15 & 12 \\
S2 & 82 & 69 & 56 \\
S3 & 15 & 14 & 10 \\
S4 & 22 & 25 & 15 \\
S5 & 108 & 48 & 41 \\
\hline
\end{tabular}

S1 hingga S5 merupakan sampel daun karet 1 hingga 5. Nilai R, G, dan B merupakan nilai rata-rata yang terbaca oleh alat ukur hasil rancang bangun yang dilakukan sebanyak 5 kali pengulangan.

Bagian daun yang sama kemudian dilakukan ektraksi. Hasil ektrak daun karet kemudian diukur nilai absorbansinya menggunakan spektrofotometer UV-Vis dengan pada panjang gelombang $\lambda 646 \mathrm{~nm}$ dan $663 \mathrm{~nm}$ dengan blanko aseton 80\%. Kemudian kadar klorofil dihitung menggunakan persamaan 2, 
sehingga didapat hasil berikut yang ditampilkan pada tabel 6 .

Tabel 6. Hasil pengukuran nilai absorbansi dan perhitungan kadar klorofil

\begin{tabular}{cccc}
\hline Sampel & $\begin{array}{c}\text { Abs. } \\
646 \mathrm{~nm}\end{array}$ & $\begin{array}{c}\text { Abs. } \\
663 \mathrm{~nm}\end{array}$ & $\begin{array}{c}\text { Klorofil } \\
(\mathrm{mg} / \mathrm{L})\end{array}$ \\
\hline S1 & 2,48 & 3,62 & 68,91 \\
S2 & 0,56 & 1,27 & 18,86 \\
S3 & 2,67 & 3,73 & 73,06 \\
S4 & 1,62 & 3,29 & 51,57 \\
S5 & 0,16 & 0,35 & 5,31 \\
\hline
\end{tabular}

Hasil pengukuran nilai RGB (tabel 5) dan spektrofotometer UV-Vis (tabel 6) kemudian dilakukan pendekatan menggunakan model pendekatan persamaan polinomial multivariabel (persamaan 3) guna mendapatkan persamaan kalibrasi. Pemodelan dilakukan untuk mencari konstanta $a_{0}, a_{1}, a_{2}, b_{1}, b_{2}, b_{3}, c_{1}, c_{2}, c_{3}$ dengan variabel $R, G$, dan B sudah diketahui melalui tabel 5 . Hasil konstanta yang didapat ditunjukkan pada tabel 7.

Tabel 7. Konstanta polonomial multivariabel

\begin{tabular}{cccccccccc}
\hline $\mathrm{a}_{0}$ & $\mathrm{a}_{1}$ & $\mathrm{a}_{2}$ & $\mathrm{a}_{3}$ & $\mathrm{~b}_{1}$ & $\mathrm{~b}_{2}$ & $\mathrm{~b}_{3}$ & $\mathrm{c}_{1}$ & $\mathrm{c}_{2}$ & $\mathrm{c}_{3}$ \\
\hline 3,5 & 2,1 & $-2,9$ & $-6,3$ & 9,3 & $-4,5$ & 3,2 & 4,8 & 4,9 & $-4,9$ \\
$\times 10^{1}$ & $\times 10^{-1}$ & $\times 10^{-4}$ & $\times 10^{-5}$ & $\times 10^{-1}$ & $\times 10^{-4}$ & $\times 10^{-7}$ & $\times 10^{-1}$ & $\times 10^{-5}$ & $\times 10^{-4}$ \\
\hline
\end{tabular}

Sehingga jika konstanta pada tabel 8 disubstitusikan ke persamaan 12 , maka

$$
\begin{aligned}
P= & (3,5)+\left(2,1 \times 10^{-1} \times R\right)-\left(2,9 \times 10^{-4} \times R^{2}\right)- \\
& \left(6,3 \times 10^{-5} \times R^{3}\right)+\left(9,3 \times 10^{-1} \times G\right)-(4,5 \times \\
& \left.10^{-4} \times G^{2}\right)+\left(3,2 \times 10^{-7} \times G^{3}\right)+\left(4,8 \times 10^{-1} \times\right. \\
& B)+\left(4,9 \times 10^{-5} \times B^{3}\right)-\left(4,9 \times 10^{-4} \times B^{3}\right)
\end{aligned}
$$

Di mana P adalah kadar klorofil model, R, G, dan B adalah variabel nilai RGB pada tabel 6 .

Kadar klorofil model kemudian dibandingkan dengan kadar klorofil aktual. Akurasi tertinggi yang dihasilkan dari kedua kadar klorofil adalah dengan nilai error sebesar 0,01\% pada sampel 5, sedangkan akurasi terendah adalah dengan nilai error 30,46\% pada sampel 4. Nilai error yang dihasilkan pada tiap sampel beragam, dan nilai error rata-rata yang dihasilkan dari 5 sampel adalah 14,50\%, sehingga akurasi yang dihasilkan melalui pemodelan polinomial multivariabel adalah sebesar $85,50 \%$.

Tabel 8. Perbandingan klorofil aktual dan klorofil model daun karet

\begin{tabular}{cccc}
\hline Sample & $\begin{array}{c}\text { Klorofil } \\
\text { aktual } \\
(\mathrm{mg} / \mathrm{L})\end{array}$ & $\begin{array}{c}\text { Klorofil } \\
\text { model } \\
(\mathrm{mg} / \mathrm{L})\end{array}$ & Error \\
\hline S1 & 68,91 & 57,04 & $17,22 \%$ \\
S2 & 18,86 & 18,72 & $0,72 \%$ \\
S3 & 73,06 & 55,45 & $24,10 \%$ \\
S4 & 51,57 & 67,28 & $30,46 \%$ \\
S5 & 5,31 & 5,31 & $0,01 \%$ \\
\hline
\end{tabular}

Hasil kedua nilai klorofil dianalisis menggunakan metode linier yang ditampilkan pada gambar 7 yang menunjukkan bahwa hasil kedua klorofil memiliki linieritas yang cukup baik, dengan koefisien korelasi sebesar 81,96\%, sehingga hasil pengukuran dari alat rancang bangun sudah baik untuk melakukan pengukuran kadar klorofil.

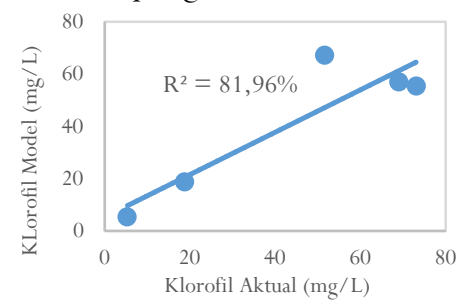

Gambar 7. Hubungan linier klorofil aktual dengan klorofil model

Nilai RGB dan nilai kadar klorofil kemudian diplot untuk melihat hubungan antara kedua nilai tersebut. Gambar 8 menunjukkan adanya hubungan antara nilai RGB dengan nilai kadar klorofil, yaitu jika nilai RGB tinggi, maka kadar klorofilnya rendah, baik klorofil aktual maupun klorofil model, dan jika nilai RGB rendah, maka kadar klorofilnya tinggi. 


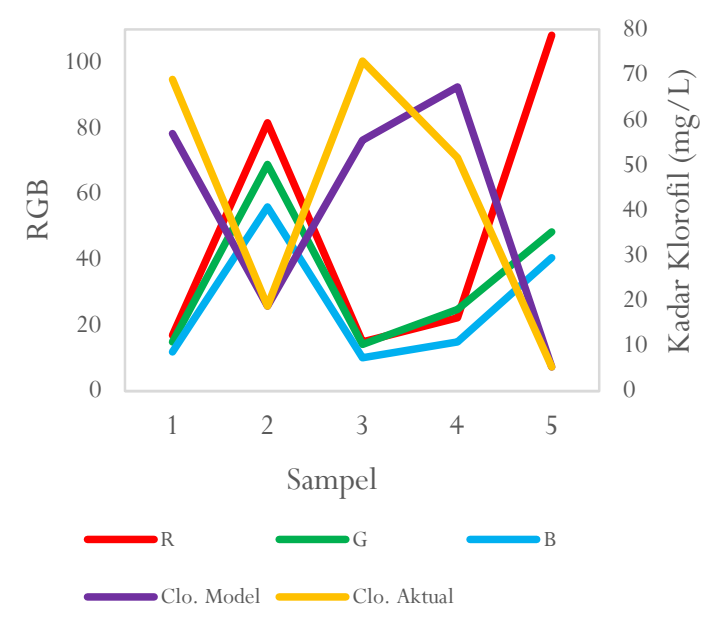

Gambar 8. Grafik hubungan antara nilai RGB dengan kadar klorofil

Nilai RGB dengan kadar klorofil aktual maupun model kemudian dianalisis menggunakan metode polinomial. Koefisien korelasi $\mathrm{R}^{2}$ nilai $\mathrm{RGB}$ dengan kadar klorofil aktual maupun model ditampilkan pada gambar 34. Koefesien korelasi $\mathrm{R}^{2}$ nilai RGB dengan klorofil aktual maupun model memiliki nilai yang baik. $\mathrm{R}^{2}$ nilai $\mathrm{R}, \mathrm{G}$, dan B dengan klorofil aktual secara berturut-turut adalah 99,9\%, 99,9\%, dan 99,6\%. $\mathrm{R}^{2}$ nilai R, G, dan B dengan klorofil model secara berturut-turut adalah 99,9\%, 100,0\%, dan 99,5\%. Hal ini menunjukkan bahwa nilai tersebut memliki respon yang baik jika menggunakan polinomial pada masing-masing nilai R, G dan B terhadap klorofil aktual maupun model.

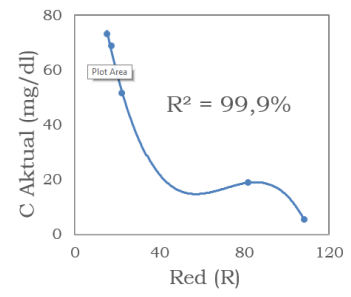

(a)

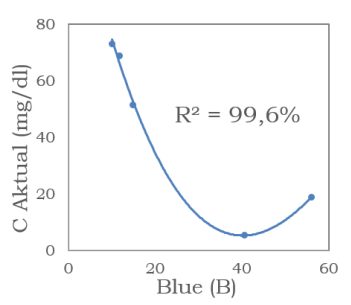

(c)

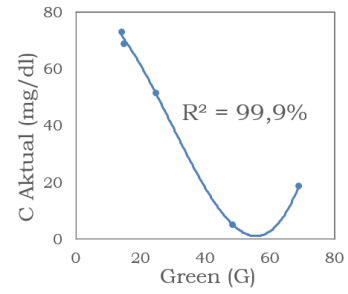

(b)

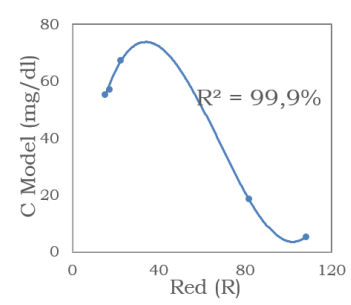

(d)

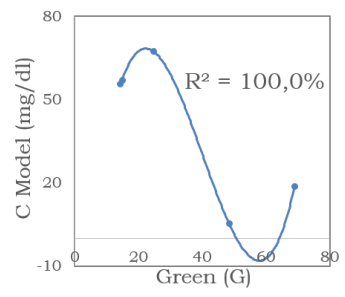

(e)

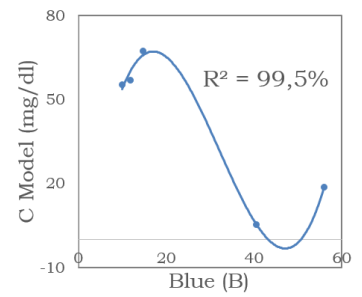

(f)
Gambar 9. (a) $\mathrm{R}^{2}$ antara nilai $\mathrm{R}$ dengan $\mathrm{C}$ aktual, (b) $\mathrm{R}^{2}$ antara nilai $\mathrm{G}$ dengan $\mathrm{C}$ aktual, (c) $\mathrm{R}^{2}$ antara nilai b dengan $\mathrm{C}$ aktual, (d) $\mathrm{R}^{2}$ antara nilai $\mathrm{R}$ dengan $\mathrm{C}$ model, (e) $\mathrm{R}^{2}$ antara nilai $\mathrm{G}$ dengan $\mathrm{C}$ model, (f) $\mathrm{R}^{2}$ antara nilai $\mathrm{B}$ dengan $\mathrm{C}$ model.

\section{KESIMPULAN}

Rancang bangun alat ukur kadar klorofil daun karet dengan metode transmisi cahaya telah berhasil dilakukan. Data output sensor berupa frekuensi gelombang kotak dengan tiga filter warna yaitu merah (R), hijau (G), dan biru (B) yang diolah menggunakan pendekatan polinomial multivariabel sehingga didapat persamaan kalibrasi. Alat ukur ini memiliki akurasi sebesar $85,50 \%$ dengan error rata-rata sebesar $14,50 \%$, dan memiliki hasil ukur yang cukup baik antara klorofil aktual dengan klorofil model dengan koefisien relasi sebesar 81,96\%.

Terdapat hubungan antara derajat warna RGB dari hasil pengukuran sensor TCS3200 dengan kadar klorofil pada daun karet. Hubungan antara nilai RGB berbanding terbalik dengan kadar klorofil. Nilai RGB akan tinggi jika kadar klorofil daun karet rendah, dan sebaliknya nilai RGB akan rendah jika kadar klorofil daun karet tinggi. Koefesien relasi antara nilai R, G, dan $\mathrm{B}$ dengan klorofil aktual secara berurutan adalah 99,9\%, 99,9\%, dan 99,6\%, dan antara nilai R, G, dan B dengan klorofil model secara berurutan adalah 99,9\%, 100,0\%, dan 99,5\%.

\section{SARAN}

Alat ukur kadar klorofil daun karet yang telah dibuat sebaiknya diberikan kemasan (casing) agar komponen yang digunakan lebih aman dan terhindar dari konslet. Diperlukan sampel daun karet yang lebih banyak ketika pengambilan data klorofil, karena jika sampel daun lebih banyak dimungkinkan bisa mendapatkan akurasi yang lebih besar. Diperlukan pengembangan metode pendekatan yang lain agar akurasi yang dihasilkan lebih besar. 


\section{DAFTAR PUSTAKA}

Andrianto, Heri, Aan D. 2016. Arduino Belajar Cepat dan Pemrograman. Bandung: Informatika Bandung.

Badan Pusat Statistik. 2018. Produksi Tanaman Perkebunan menurut Jenis Tanaman dan Kabupaten / Kota (Ton). (https://jambi.bps.go.id/site/resultTab, diakses 21 Mei 2018).

Datasheet. 2009. TCS3200, TCS3210 Programable Colour Light-to-Frequency Converter. Texas Advance Optoelectronic Solutions Inc.

Harborne, J. B. 1984. Metode Fitokimia Penuntun Cara Modern Menganalisa Tumbuhan. Bandung: ITB

Irawan, D. 2017. Pertumbuhan Ekonomi Jambi Meningkat Berkat Sawit dan Karet. (https: / / infojambi.com/pertumbuhanekonomi-jambi-meningkat-berkat-sawitdan-karet/, diakses 20 November 2017).

Rustami, E., Aisyah R. Rancang Bangun Alat Ukur Klorofil Daun dengan Metode Fluoresensi Berbasis Mikrokontroler. Omega: Jurnal Fisika dan Pendidikan Fisika 3 (1), 23 - 26 (2017), Departemen Fisika, Institut Pertanian Bogor.

Wicaksono, A. 2011. Rancang Bangun Alat Elektronik Pengukur Indeks Warna Daun Padi untuk Rekomendasi Pemupukan Nitrogen. Bogor: Intitut Pertanian Bogor.

Zhu, J., Nicolas T, Yinli L. 2012. Comparing SPAD and atLeaf Values for Chlorophyll Assessment in Crop Species. Can. J. Soil Sci., 92: 645-648, doi:10.4141/CJSS2011100. 